\title{
Book Review: The Spectacle 2.0: Reading Debord in the Context of Digital Capitalism, edited by Marco Briziarelli and Emiliana Armano
}

\author{
Lindsay Weinberg
}

History of Consciousness Department, University of California Santa Cruz, California, USA, laweinbe@ucsc.edu

Abstract: Lindsay Weinberg reviews Marco Briziarelli and Emiliana Armano (eds.) 2017. The Spectacle 2.0: Reading Debord in the Context of Digital Capitalism. London: University of Westminster Press.

Keywords: Digital Capitalism, Spectacle, Guy Debord, Digital Labour, Commodification

What use is Guy Debord's theory of the Spectacle today under digital capitalism? The essays in the edited collection The Spectacle 2.0: Reading Debord in the Context of Digital Capitalism (2017) offer an array of responses, organised around the motif of the Spectacle 2.0. The contributors draw upon a range of methodologies and Situationistinspired practices in order to examine the Spectacle - the use of mediated representations of reality for promoting the capitalist organisation of life (Debord 2009) - in the context of digital capitalism, which requires the subject's interactivity as opposed to passivity. The collection is necessary reading for scholars interested in theorising the Spectacle's relationship to the labour theory of value, commodity fetishism, and subjectivity under post-Fordism.

In his preface, "Guy Debord, Donald Trump, and the Politics of the Spectacle", Douglas Kellner assesses how media spectacles function as "tools of socio-political transformation" (2), particularly in the case of Donald Trump. Kellner attributes Barack Obama's election to his "blending [of] politics and performance in carefully orchestrated media spectacles" (3). But in their introduction to the volume, editors Marco Briziarelli and Emiliana Armano show how the analysis of the Spectacle must be situated in relation to economic transformations. Specifically, they conceptualise the Spectacle 2.0 within the shift from passivity to interactivity alongside the transition from Fordist to post-Fordist production, drawing upon the work of David Harvey and Maurizio Lazzarato. From this vantage point, Obama's success must also be attributed to the use of big data to target and actively mobilise voters (Issenberg 2012), and thus to the rise of the "attention economy" (Davenport and Beck 2002) under post-Fordism.

Tracing a genealogy from the Situationists to contemporary media theory, the editors contend that "although the Spectacle 2.0 is still founded on the core dialectical tensions defining the original Spectacle, it is reconfigured in such a way that qualitatively deserves a new taxonomy" (33). The subsequent chapters, then, take up how the dialectical struggle between labour and capital needs to be theorised in light of the rise of Spectacle 2.0.

The first set of essays, grouped under "Part I: Conceptualizing the Spectacle", develop a series of concepts for theorising the shift from the Spectacle to the Spectacle 2.0. For instance, in "The Integrated Spectacle: Towards Aesthetic Capitalism," Vanni Codeluppi draws upon the idea of aesthetic capitalism, a stage of capitalism "primarily 
centered on the ability to stimulate particularly intensely the sphere of human sensibility" (59). For Codeluppi, the aestheticisation of everyday life helps explain why the Spectacle has become "so predominant that nothing else can exist outside of it" (58). It is surprising that the essay is framed as though a close reading of films will be its primary methodology, when in fact it largely consists of, quite compellingly, a theory of the aestheticisation of social life in response to historical transformations in labour and capital accumulation strategies.

Olivier Frayssé takes a historical and bibliographical approach in "Guy Debord, a Critique of Modernism and Fordism: What Lessons for Today?" on the grounds that Debord "seldom hid his self behind his pronouncements (although they served to conceal as well), so that the biographical dimension cannot be avoided, lest we miss the praxis that brought him to theorize" (69). The essay is more persuasive when it begins to describe how the theory of the Spectacle emerged in response to Fordism and Keynesianism (74-75). Frayssé's essay also provides an interesting counterpoint to other essays in Spectacle 2.0. He contends that Debord is "irrelevant for a study of post-Fordist labour regimes" (76). Other authors in the volume disagree, and thus the edited collection provides the reader with a constellation of viewpoints to consider regarding the utility of Debord's concepts today.

Raffaele Sciortino and Steve Wright use Debord's understanding of totality, indebted to Georg Lukács, to understand new vehicles of capital accumulation in the context of the digital economy. In "The Spectacle of New Media: Addressing the Conceptual Nexus Between User Content and Valorization", the authors take Facebook as a case study for developing a theory that can encompass the role of both rent and "the free gift of users' gratuitous activity" (87, emphasis in original). One of the key insights of this essay is the way the authors nuance understandings of the digital enclosure on which rent frameworks are premised, pointing out how digital enclosures are "already human, social constructions, woven together with infrastructural capital and subjected to ongoing technological innovation" (89). Much like Lisa Gitelman and Virginia Jackson's argument that raw data is an oxymoron, always already produced under conditions of observation that are structurally and systemically integrated into the functioning of software platforms (Gitelman 2013, 6), rent through digital enclosures needs to be adequately distinguished from first-order capitalist enclosures.

Clayton Rosati's "Spectacle and the Singularity: Debord and the 'Autonomous Movement of Non-Life' in Digital Capitalism" moves the book's conversation from the question of value to the question of how to repurpose technology for inclusive/anticapitalist ends (98). Rosati is writing against superficial readings of Debord that limit the insights of the latter to a form of ideology critique grounded in false consciousness (98). Reading Debord alongside Marx, Rosati thinks about the Spectacle in relation to capital's use of Al to structure social reality for the purposes of intensifying exploitation (106-107). Ultimately, Rosati concludes that "the social conditions of life will determine the kinds of machines we build and how they mediate our relationships" (109, emphasis in original), provoking the reader to deeply consider both the possibilities and perils of an increasingly technologically mediated society.

"Part II: Phenomenology and Historicisation of the Spectacle: from Debord to the Spectacle 2.0" is largely grounded in case studies for re-theorising the Spectacle, and many of these essays also engage with the Situationists' revolutionary praxis. Barbara Szaniecki takes up Debord's analysis of the relationship between the Spectacle and urbanization in "Rio de Janeiro: Spectacularization and Subjectivities in Globo's City", applying his theory to the context of Rio de Janeiro, in which corporations are spear- 
heading the transformation of urban space to attract corporate and commercial investment. This process has involved the construction of two museums to monumentalise this effort (122). It is surprising that no mention is made of Debord's contempt for museums as anaesthetising $(2009,135)$, which would enhance Szaniecki's account of the displacement and alienation of poor urban dwellers.

In order to intervene in the spectacularisation of urban living, Jim Thatcher and Craig M. Dalton develop what they call a "detourned spectacle" (136) in "Data Derives: Confronting Digital Geographic Information as Spectacle". The authors transform the Situationist psychogeographic practice of dérive into a means of "becoming aware of and confronting 'data doubles"' (141), taking cues from Precarias a la Deriva (Precarious Women Adrift) in terms of how to build solidarities across spaces of recognised and unrecognised labour (143). They present a means of critically responding to the ways digital media collect data on users' everyday lives. While the Google Maps Timeline, their case study of choice, lends itself to dérive, this practice might not be translatable to data collection practices that are highly opaque.

The essay following Thatcher and Dalton's, "Branding, Selfbranding, Making: The Neototalitarian Relation Between Spectacle and Prosumers in the Age of Cognitive Capitalism", also looks at the Situationists' radical artistic practices. The author, Nello Barile, traces how the Situationist tactic of radical art was taken up by those trying to resist the dominance of global brands over everyday life in the 90 s and 2000s. According to Barile, despite the tendency of capitalist appropriation, there remains the possibility within maker culture - a tech-savvy artisanal culture with practical know-how and relative self-determination over their craftsmanship - of responding through détournement. Alternatively, he proposes a "neototalitarian system that incentivizes the production of authenticity as its main resource" (164). The latter option seems like an undesirable attempt to reform the system from within, reducing alienation within a society still driven by capitalism, and thus, exploitation.

Chiara Bassetti, Maurizio Teli, and Annalisa Murgia's essay, "Tin Hat Games - Producing, Funding, and Consuming an Independent Role-Playing Game in the Age of the Interactive Spectacle," is also concerned with investigating the revolutionary potential of new social formations under the Spectacle 2.0. The essay's central ethnographic case study is Tin Hat Games, "a small association of independent game designers, producers and promoters" (169). For the authors, Tin Hat Games' strategy of countergaming, where games are designed to serve as explicit forms of social critique, is nonetheless complicit in gamified capitalism - the instrumentalisation of people's affective attachments to fun and play - in that they rely on social media firms for publicity and participation (169). This essay helps readers understand the ambivalence that characterises the Spectacle 2.0; while consumption practices may have become more "authentic" or interactive, they are nonetheless subject to exploitation.

Romina Surugiu's “'Freelancing' as Spectacular Free Labour: A Case Study on Independent Digital Journalists in Romania" explores a similar tension at work under contemporary spectacular society. While on the one hand, the Romanian independent digital journalists Surugiu interviews are actively working to undermine the Spectacle by resisting the corruption, editorial constraints, and imperatives of mainstream media, these journalists still "peripherally integrate themselves in the institutionalized system of ideology, by applying for fellowships and prizes offered by nongovernmental structures" (192). Surugui concludes that "through their activity, as apparently independent critics and free labourers, they may lend an appearance of legitimacy to the institutionalized system of ideology" (193), leaving the reader with the sense that these journal- 
ists have no way to effectively resist the Spectacle. However, other essays in the collection stress the power of Situationist tactics, and thus the inclusion of Surugui helps the volume feel balanced as opposed to pessimistic.

Jacob Johanssen is also concerned with the role of labour under the Spectacle 2.0. He uses Debord's theory of the Spectacle to understand the exploitation of reality show participants. The essay focuses on the show Embarrassing Bodies, a "medical reality show that features patients with common but also very rare medical conditions" (100). Johanssen argues that patients' bodies are exploited for viewers' consumption and critique under neoliberal society. There is an interesting tension at work in the essay, as the reader is given detailed accounts of participants' ailments and operations, with descriptions of the doctors' invasive questioning. The reader is left wondering whether the representation of the episodes, themselves part of a commodity (in this case, a book for purchase), fit into the author's theory of exploitation.

The final essay, "Disrupting the Spectacle: The Case of Capul TV During and After Turkey's Gezi Uprising" by Ergin Bulut and Haluk Mert Bal serves as a nice complement to Surugiu in that both essays take ethnographic approaches to examine journalism outside the US. Bulut and Bal interview the founders of Capul TV, a group of media activists whose coverage of the violent suppression of the Gezi Park Protests helped encourage a nationwide series of uprisings. The authors explain that Capul TV relies on the free labour of activists, a deliberate rejection of wage labour in favour of collaborative and freely given activist participation, which functions as a network rather than a hierarchically organised movement (222). Their practices include détournement, such as the appropriation of words associated with dominant media discourses (213), emphasising the possibility of resisting the Spectacle 2.0.

What would it mean, then, to think of The Spectacle 2.0: Reading Debord in the Context of Digital Capitalism in relation to détournement? As a mode of writing, détournement is radical in both form and content, "aware of its inability to enshrine any inherent and definitive certainty" (Debord 2009, 206). Détournement actively resists ideological and conceptual rigidity because, following Fredric Jameson, "it is inevitable that every theory about the world, in its very moment of formation, tends to become an object for the mind and to be invested with all the prestige and permanency of a real thing in its own right, thus effacing the very dialectical process from which it emerged" $(1972,57)$. Debord reengages the theory of the past in order to mobilise it, working against the tendency for ideas to develop a sense of permanency outside the dialectical struggle. The Spectacle 2.0 should be read in this tradition. It is up to the reader to treat the edited collection not as an object of permanency, but as a set of malleable conceptual tools for engaging in class struggle under digital capitalism.

\section{References}

Davenport, Thomas H. and John C. Beck. 2002. Attention Economy: Understanding the New Currency of Big Business. Cambridge, MA: Harvard Business Review Press.

Debord, Guy. 2009. Society of the Spectacle. Eastbourne: Soul Bay.

Gitelman, Lisa, ed. 2013. Raw Data is an Oxymoron. Cambridge, MA: MIT Press.

Issenberg, Sasha. 2012. "How Obama Used Big Data to Rally Voters." MIT Technology Review. Accessed 05 March 2018. https://www.technologyreview.com/s/508836/howobama-used-big-data-to-rally-voters-part-1/

Jameson, Fredric. 1972. Marxism and Form: Twentieth-century Dialectical Theories of Literature. Princeton, NJ: Princeton University Press. 


\begin{abstract}
About the Author
Lindsay Weinberg

Lindsay Weinberg is a PhD Candidate in the History of Consciousness Department at the University of California, Santa Cruz. Her dissertation is an interdisciplinary analysis of personalisation, meaning the web of technologies and cultural practices that generate information about consumers to market goods and services to target audiences. Her research interests include the history of leisure-time surveillance, discourses concerning possessive individualism and privacy, and content moderation online. Her work has appeared in Lateral and Westminster Papers in Communication and Culture. She is also the contributing editor of Studies In Control Societies.
\end{abstract}

